\title{
O transtorno de personalidade borderline na Daseinsanalyse de Alice Holzhey-Kunz
} Borderline personality disorder in Alice Holzhey-Kunz's Daseinsanalysis

\author{
Paulo Eduardo Rodrigues Alves Evangelista ${ }^{1}$
}

\section{Resumo}

A primeira geração da Daseinsanalyse é conhecida. Inaugurada por Ludwig Binswanger, que assume a descrição da existência (Dasein) feita por Heidegger em Ser e tempo, para interpretar as psicopatologias como projetos de mundo, é desenvolvida por Medard Boss, com ajuda do próprio filósofo, nos Seminários de Zollikon. Este artigo objetiva apresentar reformulações propostas pela daseinsanalista suíça Alice Holzhey-Kunz (1943 - ), ex-aluna de Boss, que interpreta as psicopatologias como modos de "sofrer do próprio ser", ou seja, modos nos quais o existir irrompe e revela-se a condição existencial. Ou seja, em experiências psicopatológicas, o entendimento ontológico do próprio ser (pré-inclusão ontológica), costumeiramente encoberto na ocupação, torna a existência cotidiana inviável, exigindo "manobras ônticas" - comportamentos e mecanismos que visam neutralizar caracteres ontológicos, de início fadados ao fracasso. Para melhor ilustrar, apresento e discuto a interpretação de Holzhey-Kunz para o Transtorno da Personalidade Borderline, recorrendo a um caso clínico.

Palavras-chave: Daseinsanalyse; Transtorno de Personalidade Borderline; Psicopatologia

\begin{abstract}
The first generation of Daseinsanalists is well known. Daseinsanalysis is inaugurated by Ludwig Binswanger, who takes Heidegger's description of existence in Being and Time to interpret psychopathologies as world-projects, and later developed by Medard Boss with the philosopher's help in the Zollikon Seminars. This article aims to present reformulations proposed by swiss daseinsanalist Alice Holzhey-Kunz (1943 - ), Boss' ex-student. She interprets psychopathologies as modes of "suffering one's own being", i.e., they are modes of being in which the existential condition erupts and reveals itself. In psychopathological experiences, ontological understanding of one's own being (pre-ontological inclusion), usually screened out by occupation, makes daily existence difficult and demanding 'ontic maneuvers' - behaviors and mechanisms aiming to neutralize ontological aspects, but bound
\end{abstract}


to fail from the start. To better illustrate it, I present and discuss Holzhey-Kunz's interpretation of Borderline Personality Disorder articulated with a clinical case.

Keywords: Daseinsanalysis; Borderline Personality Disorder; Psychopathology

${ }^{1}$ Universidade Paulista - UNIP - São Paulo (SP), Brasil; Pontifícia Universidade Católica de São Paulo - PUC - São Paulo (SP), Brasil. E-mail: paulo.e.evangelista@ gmail.com

Recebido: 19/6/2017

Aceito: $12 / 9 / 2017$ 


\section{Introdução}

Nascida em 1943, formada em História e Filosofia em Zurique (1971), Holzhey-Kunz conclui formação em 1976, no Instituto Daseinsanalítico para Psicoterapia e Psicossomática, fundado por Medard Boss, mas em 1983 rompe com o Instituto e se junta à Sociedade para Antropologia Hermenêutica e Daseinsanalyse, que hoje preside e onde coordena os Seminários Daseinsanalíticos de Zurique.

A Daseinsanalyse de Holzhey-Kunz está em consonância com a proposta original de Medard Boss de que o sentido da psicoterapia é "dar espaço ao paciente para o desenvolvimento, que tem sido, até então, perdido ou evitado" (Holzhey-Kunz, 2014, p. 25, tradução do autor), recorrendo, para isso, à técnica psicanalítica clássica: a livre associação.

A divergência de Boss com Freud era quanto à “concepção de homem” e ao modelo epistemológico; no lugar das explicações causais científico-naturais (determinação do Inconsciente reificado), a fenomenologia aparece como método e a existência (cujo ser é seraí), no lugar de um psiquismo mecânico. Holzhey-Kunz, por sua vez, considera limitada e limitante a fenomenologia em Boss por, segundo ela, abrir mão de seu caráter hermenêutico. Sua Daseinsanalyse reabilita a interpretação no processo psicoterapêutico. Segundo ela, a fenomenologia heideggeriana é hermenêutica, o que significa que está comprometida com trazer à luz significados e sentidos ocultos. Recorre ao $\$ 7$ de Ser e tempo (Heidegger, 1927/2012) para se justificar; lá, o filósofo afirma que a fenomenologia é o método para fazer ver o ser dos entes, que se encontra, no mais das vezes, velado. Da mesma forma, o ser da existência permanece, no mais das vezes, velado, encoberto, distorcido, sendo necessária a fenomenologia hermenêutica para o fazer ver.

O zelo excessivo de Medard Boss para não deixar que pressupostos invadissem a mostração direta dos fenômenos o impediu de assumir a hermenêutica como método de acesso ao sentido do sofrimento existencial. Seu objetivo, segundo Holzhey-Kunz, era “implementar uma 'patologia apropriada ao Dasein'," (Holzhey-Kunz \& Fazekas, 2012, p. 37, tradução do autor), o que ele faz com apoio do filósofo Heidegger. Fornece, assim, bases "mais apropriadas ao Dasein" para a medicina, permanecendo, entretanto, preso ao modelo médico de insistir numa definição de doença, no caso, do ser-doente, como restrição em possibilidades existenciais (Holzhey-Kunz \& Fazekas, 2012). Com isso, ele teria abolido a interpretação da relação psicoterapêutica. 
A Daseinsanalyse de Holzhey-Kunz posiciona-se contrariamente a Boss nesse quesito, mas modificando o sentido da interpretação. Assim como na psicanálise e na Daseinsanalyse, os sintomas têm significados que podem ser explicitados. Mas, diferentemente da psicanálise freudiana, o sofrimento existencial, indicado nos sintomas, não é fruto de reminiscências e, sim, da condição de ser-aí (Dasein). Os sintomas têm um sentido inconsciente, uma intenção oculta, cujo sentido pode ser desvelado pela fenomenologia hermenêutica na psicoterapia: responder à condição humana.

Holzhey-Kunz (2014) reconhece o mérito de Freud de inaugurar uma nova interpretação dos sintomas psiquiátricos. Diferentemente da tradição médica, que operava no eixo saúde-doença e normal-desviante, Freud propõe a existência de um sentido oculto para os sintomas, abrindo a possiblidade de, via hermenêutica, descobrir o que significam. Na psicanálise freudiana, são dois os sentidos do sintoma: seu "de onde" e seu "para quê". O "de onde" aponta para a proveniência histórica, de modo que um sintoma atual está ligado a uma experiência passada. O "para quê" indica uma intenção. Enquanto a psicanálise freudiana acabou se concentrando no "de onde" (experiências infantis determinantes), a Daseinsanalyse dedica-se ao "para quê", ao "a fim de quê" do comportamento tido como sintomático, ou seja, interpretando o sentido da ação, o que essa existência realiza, cumpre, agindo como age. $\mathrm{O}$ sofrimento existencial não é passivo, portanto. É um modo de lidar com o próprio existir.

\section{Sofrer pelo próprio ser}

A descrição fenomenológica da existência realizada por Heidegger, em Ser e tempo, revela o caráter autoencobridor do próprio ser. Segundo Heidegger, "o que é onticamente mais próximo e conhecido é ontologicamente mais longínquo, não conhecido e constantemente deixado de lado, em sua significação ontológica" (Heidegger, 1927/2012, p. 145, §9). Ou seja, o existir cotidiano, perdido nos afazeres e na (auto)interpretação pública (o Impessoal), encobre sua própria condição (seu ser), mas esse encobrimento é parcial, pois o ser da existência não eliminado é distorcido e compreendido equivocadamente, mas permanece inextirpável. Holzhey-Kunz interpreta o sofrimento existencial à luz de a existência (Dasein) ser sujeita a (o que ela chama de) "experiências de ser" (Holzhey-Kunz, 2014, p. 47), situações que indicam a condição de ser-aí finito, dejecto no mundo público, tendo que ser unicamente responsável por si, a cada vez, corpóreo, em relação com outros e sujeito à angústia (experiência reveladora do próprio ser). 
Holzhey-Kunz lança mão de algumas análises de Sartre para complementar a analítica existenciária de Heidegger, como a análise do ser-relação-com-outros (ser-para-si, ser-para-ooutro), experiências inconscientes, como má-fé. Ela critica Boss por permanecer nos limites das descrições heideggerianas. Algumas diferenças entre a Daseinsanalyse de Holzhey-Kunz e Boss surgem em razão dessa ampliação na compreensão de existência.

As experiências de ser são possíveis em razão da "inclusão" ou "implicação" préontológica" (pre-ontological inclusion) (Holzhey-Kunz, 2014, p. 47) do Dasein, ou seja, o implícito entendimento de seu ser, que funda toda possibilidade existencial (ôntica). A existência é ôntico-ontológica, o que significa que, em todo modo de ser-no-mundo (ôntico), o ser do ser-aí (ontológico) se dá, 'realizando', por assim dizer, seu ter-que-ser. Nas palavras de Heidegger em Ser e tempo: "Expressa ou não, adequada ou inadequadamente, a existência é de algum modo concomitantemente entendida. Todo entendimento ôntico tem suas ‘pressuposições’ (Einschlüsse)”' (Heidegger, 1927/2012, p. 851, §63).

$\mathrm{Na}$ analítica existenciária de Ser e tempo, a tarefa hermenêutica fenomenológica é de arrancar do encobrimento das interpretações públicas cotidianas e fazer ver o ser da existência, do qual o ser-aí foge, a cada vez. A psicoterapia daseinsanalítica de Holzhey-Kunz assume, como, tarefa deixar e fazer ver a condição de ser-aí que se insinua no sofrimento existencial, mas que é constantemente combatida por modos de ser-no-mundo encobridores, a fim de que a existência possa se assumir mais livremente.

Holzhey-Kunz exemplifica a inclusão pré-ontológica com situações banais: o desejar "bom dia" a alguém inclui (traz implícito) o fato de que não há garantias de como ele será. Dizer "saúde" quando alguém espirra inclui (implica) o poder adoecer e morrer, manifesto no espirro. A existência "sabe" que seu ser está constantemente ameaçado; o ser-ameaçável (poder-não-ser) é constitutivo do existir.

Nesse sentido, o decair na cotidianidade é uma "proteção contra a incursão de experiências de ser insuportáveis (overtaxing) no cotidiano" (Holzhey-Kunz, 2014, p. 51, tradução do autor), é uma defesa contra a verdade ontológica, um modo de filtrá-la (screen out) e bloqueá-la. As interpretações d'a gente, que tomam a existência por substância e fornecem explicações apaziguantes, são necessárias para o cotidiano. Sem elas, o cotidiano seria impossível. Por esse motivo, são ativamente buscadas e atualizadas.

Holzhey-Kunz indica três modos de proteção contra irrupções de experiências ontológicas: a ocupação cotidiana, o senso comum e os sentidos culturais. Na ocupação Psicopatologia Fenomenológica Contemporânea, 2017;6(2):145-157 
cotidiana, a existência se esquece de si, absorvida por aquilo em que se ocupa. A existência, de início, e no mais das vezes, compreende-se à luz das ocupações. Quanto mais envolvido, mais seguro contra experiências de ser. O senso comum - o a gente (das Man) de Ser e tempo - fornece máximas, expressas em ditados, que orientam, substitutivamente, a vida cotidiana e cada cultura tem interpretações compartilhadas para as experiências básicas existenciais. A nossa época (Era da Técnica) fornece uma multiplicidade de interpretações e sentidos para cada um apoiar sua vida, o que, por um lado, amplia o leque de visões de mundo encobridoras, mas, por outro, aumenta a carga do ter que fazer-se de cada indivíduo. Estes três modos são coletivos, isto é, a gente (das Man) se protege contra experiências ontológicas.

O sofrimento existencial é um modo de lida com experiências de ser. A pergunta sobre a proveniência do sofrimento neurótico é respondida por Holzhey-Kunz: “o neurótico sofre por seu próprio ser" (Holzhey-Kunz, 2014, p. 145, tradução do autor). Trata-se de um modo específico de relação com o ser-aí, por qual os mecanismos compartilhados de encobrimento da condição falham. Assim, o neurótico se mostra alguém mais sensível ao seu ser, mas sofre por estar à mercê do que a ele se revela.

A palavra sensibilidade tem a vantagem de expressar, em termos positivos, aquilo que faz a pessoa em sofrimento sofrer: saber, ouvir (e ver) mais que a média, implicando (including) relação com coisas inteiramente concretas na vida cotidiana. Alguém que esteja em sofrimento mental está orientado para experiências que a pessoa saudável não tem, ou, pelo menos, não da mesma maneira, porque a pessoa saudável não está, de modo algum, preocupada com assuntos ontológicos na vida cotidiana (Holzhey-Kunz, 2014, p. 146, tradução do autor) .

Os quadros chamados de psicóticos diferem dos neuróticos. Na psicanálise, isso se deve a diferenças na estruturação do psiquismo. Na Daseinsanalyse, isso não faz sentido; a única 'estrutura' é a existência. Portanto, também os modos de ser psicóticos devem ser entendidos como modos específicos de lida com o próprio ser, fundados numa sensibilidade maior que a média para seu ser-aí. 


\section{$O$ caso de Aline}

A fim de explorar a interpretação daseinsanalítica de Holzhey-Kunz, recorro à história do breve processo psicoterapêutico de Aline $^{1}$, que tive a oportunidade de supervisionar, no estágio clínico na universidade onde leciono. Os fenômenos clínicos foram interpretados à luz da Daseinsanalyse de Medard Boss, focando os entes que aparecem e como aparecem, na clareira de mundo que Aline é, considerando possibilidades recusadas e renunciadas e explorando o sentido desse posicionamento. A retomada que proponho, agora, visa identificar, se possível, as implicações ontológicas no cotidiano de Aline.

Aline procurou a clínica-escola por indicação do hospital, que condicionou sua alta médica ao início de processo psicoterápico. Tentou se suicidar, ingerindo remédios com bebida alcoólica. Em seguida, contatou seu namorado, que foi socorrê-la. Está há três anos sem trabalho nem estudo, desde que concluiu o ensino médio. Tem 20 anos. Traz consigo a receita médica do hospital psiquiátrico onde foi atendida, indicando, como hipóteses diagnósticas, borderline e bipolaridade.

Mora com sua avó paterna, com quem sua mãe a deixou após o divórcio, quando ainda era bebê. Seu pai foi embora para sua cidade natal, no Nordeste, e não mantêm contato. Antes disso, ele morou na casa da avó de Aline, com sua nova esposa. Ela e a madrasta brigaram muito, agredindo-se fisicamente. Sua mãe a procura esporadicamente. Sua irmã, cinco anos mais nova, mora com ela e tem apresentado comportamentos de automutilação, como a própria Aline, desde a mesma idade.

Tem um namorado, com quem chegou a morar por alguns meses, após uma briga com a avó. Tiveram muitos conflitos e dificuldades para pagar as contas, o que o motivou a voltar para a casa de sua mãe, ocasionando uma grande briga com Aline, que a fez voltar para a casa da avó. Em suma, Aline tem conflitos com todas as pessoas com quem convive e que a sustentam.

Vem muito arrumada, bem vestida e maquiada, para as sessões. Preocupa-se com sua aparência física; vê-se magra demais, acha suas pernas finas e feias, seus seios pequenos. Ao longo das sessões, realiza somente uma das metas a que havia se proposto: uma tatuagem com um ideograma japonês, significando "liberdade", que simboliza, para ela, seu maior desejo.

\footnotetext{
${ }^{1} \mathrm{O}$ nome e os dados biográficos foram todos alterados, a fim de impedir identificação, guardando o sigilo da paciente.
} 
Sofre por não conseguir juntar dinheiro para fazer implantes de silicone nos seios, o que a deixaria mais "gostosona" (expressão dela) para o namorado.

A relação com ele é, para ela, a principal questão na psicoterapia. Sente muito ciúmes, monitora-o por celular e não suporta imaginar o que ele pode fazer com todas as mulheres que frequentam a academia onde trabalha. Tem sonhos frequentes, em que o vê tendo relações sexuais com outras mulheres. Sente ódio nesses sonhos. Outras vezes, não consegue dormir, imaginando vividamente essas cenas. Apresenta-o como seu único amigo. Tem muito medo de perdê-lo. Diz à psicóloga que esperar tornar-se como ela: calma, tranquila e decidida. Ela se vê insegura, inconstante, explosiva, incapaz de concluir qualquer atividade a que se proponha. Quer cursar faculdade, mas não consegue decidir qual. Em outros momentos, quer ser atriz. Não inicia em nenhuma direção, impedida pela indecisão e falta de recursos. Sua única atividade é frequentar a academia.

No começo do processo, briga com a avó paterna e muda-se para a casa da avó materna. Isso não chama tanto sua atenção, quanto as brigas com o namorado. Passou tempo com o namorado no fim de semana, mas brigaram porque ele não vê chances de voltarem a morar juntos em breve. Interpreta que ele não quer nunca mais morar com ela, que não a deseja mais. Entende assim o fato de ele ter trocado a senha do celular, o que ela descobre enquanto está no banheiro, e de ele ir embora ao final da tarde de domingo, ao invés de ir à noite. Em outras sessões, as brigas são motivadas por ele chegar mais tarde que o combinado, por ficar preso no trabalho, etc. Acha que a mãe dele o incentiva a terminar o namoro.

Não comparece à terceira sessão. As faltas se tornarão mais frequentes no próximo mês e a psicoterapia será encerrada por desistência, já que parou de vir e não atendeu aos chamados da clínica. Na quarta sessão, mostra-se novamente próxima da psicoterapeuta, dizendo que gosta muito dela e que veio em consideração a ela, pois estava muito cansada, como na sessão anterior.

Queixa-se de não ter apoio de ninguém para seus projetos e atribui a isso sua dificuldade para estudar e trabalhar. Explica-se à luz da história de abandonos e conta que espera de seu namorado esse suporte, mas ele sempre falha com ela.

Na sétima semana, tem nova briga com a avó materna, pois sente que suas tias maternas a cobram para que trabalhe. Empacota suas coisas, vai em direção à porta, mas a avó a impede. Permanece lá, imaginando quando o namorado a chamará para ir morar com ele. 
A partir de então, começa a chegar com 40 minutos de atraso. Fala que tem muita coisa para contar, mas que contará na próxima semana. Quando não atrasa, falta sem avisar. Após três semanas sem notícias de Aline, a psicoterapia é considerada encerrada.

\section{O que o existir de Aline revela (interpretação daseinsanalítica do modo de ser borderline)}

Aline sofre pelo próprio ser. São dois os temas que sobressaem nas sessões: sua relação com os outros e o modo como lida com sua condição de ter-que-ser. Ambos os temas estão, evidentemente, interligados.

As relações com os outros são todas marcadas por conflito. Sua história (e o modo como se apropria dela e a narra) realça o ter sido abandonada por pai e mãe. As relações com os familiares são marcadas por brigas. Por um lado, a sustentam, fornecem casa e comida, por outro, sente-se cobrada para trabalhar, para fazer algo com sua vida. Esses modos de o outro aparecer para ela alternam-se rapidamente e ela age correspondentemente. A situação de moradia logo se torna pesada demais para Aline, que briga e sai de casa, indo morar com outro familiar. Ou seja, depende dos outros, mas essa dependência lhe é insuportável.

Com o namorado, isso fica ainda mais claro; espera dele apoio e suporte e sente, a todo momento, que sua relação está ameaçada, seja por outras mulheres, seja pela mãe do rapaz, seja por ela mesma. Na tentativa de suicídio, estão presentes esses dois modos de se relacionar: tenta findar seu relacionamento, matando-se, e pede que ele a salve e ao relacionamento, colocando-se sob seus cuidados.

Holzhey-Kunz chama a atenção para o fato de que, do ponto de vista ontológico, o sercom-outros é condição, conforme descrito por Heidegger em Ser e tempo, mas, no cotidiano, está sujeito ao ter-que-ser, que funda toda possibilidade ôntica, isto é, as relações com outros são feitas e refeitas a cada vez. Perfazem todas as relações com outros as seguintes perguntas:

O que este Outro específico significa para mim, o que eu sinto por ele, o que eu penso sobre ele, como eu o avalio, que uso tenho para ele, o que quero dele, o que posso, realisticamente, esperar dele, etc.?; e, do mesmo modo: o que significo para este específico Outro, o que ele sente por mim, o que ele pensa sobre mim, como ele me avalia, o que ele quer de mim, etc.? (Holzhey-Kunz, 2014, p. 86, tradução do autor). 
Com base nessas perguntas implícitas, as relações concretas com os outros vão se formando e os modos de relação com cada qual, se constituindo. Na relação com o namorado, há uma expectativa de agradá-lo, para mantê-lo junto a si, esperando que ele seja o suporte para a concreção de planos e desejos pessoais. Aline cumpre isso cuidando de sua aparência física (que, para ela, está aquém do necessário) e tentando controlar seu namorado, monitorando-o por celular. Os conflitos com ele acontecem constantemente, pois, para ela, mostra-se o que está implicado (incluído) em toda relação: que o Outro, como si mesmo, é livre para se relacionar comigo, ou não, isto é, que nenhuma relação está, de antemão, assegurada. Ela sofre pela incerteza constitutiva de todo relacionamento, encoberta cotidianamente por juras de amor, por contratos, por determinações, etc. Aline luta contra essa condição ontológica tentando assegurar-se de sua relação. Fantasia o morar junto como garantia de um lar e uma relação fixa, contrariamente à sua história e ao seu cotidiano.

Seu medo de perder o namorado ou de perder as relações com familiares invade seu cotidiano e seu mundo onírico e tira-lhe o sono. A perda da relação é uma ameaça constante. O que funda esse medo é a condição ontológica de estranheza, de não-ser-em-casa (unheimlichkeit), manifesta nas raras experiências de angústia. $\mathrm{O}$ encontrar abrigo e constituir um lar na vida são um modo de encobrir essa estranheza fundamental. Aline, porém, não consegue filtrar (screen out) essa ameaça e fica subjugada por ela, que se manifesta a todo o momento; a distância do namorado indica a perda da relação, assim como sua proximidade indica o risco de perda. Esta situação evidencia o que Holzhey-Kunz chama de 'baixa tolerância à angústia'. Por ser ameaçadora, a angústia é transformada, muito frequentemente, em medo. O medo é tolerável, pois contra o que amedronta há recursos possíveis para afastar, recuperando a sensação de segurança. Se o perigo é perder o namorado, por ele não a achar desejável, pode se cuidar para parecer mais "gostosona" (expressão dela). Se o risco é o que ele pode fazer à distância, pode monitorá-lo ou mantê-lo perto, etc. No caso de pacientes com maior sensibilidade à angústia (ou baixa tolerância à angústia), todo medo é revelador da estranheza, o que difunde a ameaça. O "mecanismo de defesa" que transforma a ameaçabilidade constitutiva do existir (angústia) em medo de algo do interior-do-mundo não é eficaz. Isso faz com que qualquer situação se torne ameaçadora para ela, como, por exemplo, a cobrança de alguma tia para que trabalhe, um olhar torto de uma avó, etc., inviabilizando qualquer projeto pessoal. 
Articula-se, com isso, a outra dimensão existencial que se manifesta constantemente em sua vida, mas que, de modo geral, permanece encoberta na existência cotidiana: o ter-queser. O ser-preocupação do Dasein é a articulação de existenciaridade (poder-ser), factualidade (já ser em) e decair (ser junto a), ou seja, está sob responsabilidade de cada existência fazerse, a partir das situações em que se descobre sendo. Essa é a liberdade existenciária, segundo Heidegger. Na existência cotidiana, o que é o fundamento de toda transformação pessoal permanece encoberto. A sensibilidade à condição, isto é, a experiência ontológica do ter-queser pode ocasionar o "sofrer pela própria fraqueza" (Holzhey-Kunz, 2014, p. 160, tradução do autor). A condição de ser-aí é ter-que-ser dejecto. Sendo ontologicamente indeterminada, cada existência precisa fazer-se, mas não tem liberdade total nessa 'construção', pois é sujeita a estar já situada. O sofrer por essa dimensão paradoxal da finitude - a factualidade - HolzheyKunz chama de sofrer pela fraqueza da própria subjetividade. Há duas fugas aparentemente possíveis: regressar à situação anterior, ao assumir responsabilidade pelo próprio ser, ou fugir para além dela, assumindo-se com um poder de livre criação e determinação de si, do mundo, dos outros. Este segundo caminho exige a sustentação dessa autoimagem contra toda e qualquer situação ordinária, que, por condição, a confronta e a ameaça. Ambos os caminhos são manobras ônticas fadadas ao fracasso, pois a condição de ter-que-ser é inexorável.

Aline tem sensibilidade aguçada para o ter-que-ser. Ela sente que sua existência está unicamente sob sua responsabilidade. É ela quem tem que fazer suas escolhas profissionais e pessoais e ela "sabe" que escolher é renunciar, daí a dificuldade para aderir a qualquer projeto. Ela não se sustenta lançando-se em direção a um possível, pois é sensível à falta de garantias que perfaz o existir, tendo em sua história uma coleção de perdas e interrupções. Há mecanismos compartilhados encobridores das possíveis rupturas e da falta de garantias, mas Aline não adere a eles. Pelo contrário, sente o peso de todo começar algo e, como risco de perda de independência, todo envolvimento com algo ou alguém. Permanecendo como iniciante, ou mesmo antes de iniciar, sente-se resguardando sua autonomia.

Sua lida com o ter-que-ser alterna os dois modos indicados por Holzhey-Kunz. Ora foge para a fantasiosa situação que antecede o descobrir-se responsável por seu ser e entrega suas decisões ao namorado, à família, à vida de modo geral, ou age na direção de suprimir esse ter-que-ser, ora assume um fantasioso poder ilimitado de determinação de si e dos outros. Nas relações com outros, essa atitude gera conflitos, pois os outros escapam à determinação de Aline; as avós não são o suporte que ela determina que sejam, o namorado não é o marido 
fiel e suportivo que ela determina que seja. Quando o Outro confronta sua determinação, o que advém é ameaça à sua existência. Aline reage a isso com agressividade, forçando para que o Outro seja como ela determina, mas isso afasta o Outro, ameaçando-a. Sua admissão de culpa reaproxima o Outro, mas é assunção de sua fraqueza, o que, novamente, a ameaça e compromete sua relação com o Outro.

Não terá sido esse modo de ser-com um motivo para o abandono da psicoterapia? Pois Aline inicia o processo psicoterapêutico aparentemente disposta a envolver-se, estabelecendo uma relação direta com a psicoterapeuta, colocando-se sob seus cuidados, esperando orientações. Entretanto, logo esse ímpeto inicial esmorece e, por mais que ela tente seduzir a psicóloga, prometendo temas interessantes nas sessões seguintes, abandona o processo. Terá o envolvimento com a psicóloga já lhe suscitado as possibilidades de dependência, perda e separação, ameaçadoras de sua autonomia? Essas perguntas não podem ser respondidas, pois Aline nunca mais procurou a clínica-escola.

\section{Conclusão}

O objetivo desta análise não foi o de diagnosticar Aline e, sim, apresentar seu modo de ser, articulando-o com a compreensão daseinsanalítica de Holzhey-Kunz para o transtorno de personalidade borderline. Para a autora, é a compreensão do sentido do sofrimento "psíquico" que diferencia as abordagens psicopatológicas. Para ela, o sentido é uma sensibilidade aguda para a condição ontológica implicada em cada experiência cotidiana, de modo que as pessoas em "sofrimento psíquico" sofrem pelo próprio ser. Já para a filosofia de Heidegger (e outras existenciais), é uma decidida investigação do próprio ser, que exige essa mesma sensibilidade. O paciente psicopatológico é alguém que sofre por isso, pois é vitimado, invadido por experiências ontológicas, que tornam o cotidiano difícil, quando não, insuportável.

Na tradição psicanalítica, o transtorno de personalidade borderline depende de uma divisão entre personalidades neurótica e psicótica, pressupondo estruturações psíquicas distintas. Do ponto de vista daseinsanalítico, essas divisões são abstrações fundadas em teorias encobridoras da existência. Todos os modos de sofrimento psicopatológico são modos de existir, que podem ser descritos à luz de como se lida com seu ser-aí. O transtorno de personalidade borderline é uma categoria nosológica para um modo de existir, caracterizado por baixa tolerância ao medo, suscitando a revelação da estranheza originária do existir e o 
sofrer o paradoxo de ter que se criar (ser autônomo e potente), dentro de limites já dados (ser impotente), o que Holzhey-Kunz chama de sofrer pela própria fraqueza.

\section{Referências}

Heidegger, M. (1927/2012). Ser e Tempo. (F. Castilho, Trad.) Campinas: Editora da Unicamp; Petrópolis, RJ: Editora Vozes.

Holzhey-Kunz, A. (2014). Daseinsanalysis. (S. Leighton, Trad.) Great Britain: Free Association Books.

Holzhey-Kunz, A., \& Fazekas, T. (2012). Daseinsanalysis: a dialogue. Em L. Barnett, \& G. Madison, Existential Therapy - Legacy, Vibrancy, and Dialogue (pp. 35-52). London and New York: Routledge. 